\title{
A prática como componente curricular na formação de professores em ciências biológicas: 0 que revelam as teses e dissertações
}

Juliana Moreira Prudente de Oliveira

julifari@yahoo.com.br

orcid.org/0000-0002-5301-3513

Universidade Estadual do Oeste do Paraná (UNIOESTE), Cascavel, Paraná, Brasil

Dulcinéia Ester Pagani Gianotto depgianoto@uem.br

\section{orcid.org/0000-0001-8327-9147} Universidade Estadual de Maringá (UEM), Maringá, Paraná, Brasil.

\section{RESUMO}

A formação de professores é um importante objeto de pesquisa na área do ensino de Ciências. No entanto, a prática como componente curricular (PCC), constitui-se um tema que ainda gera muitas dúvidas nos formadores de professores. Portanto, neste artigo buscou-se quantificar as produções - teses e dissertações - envolvendo a temática PCC e também investigar quais os apontamentos presentes nas produções da área de ensino de Ciências e Biologia. Para isso, realizou-se uma pesquisa documental por meio da busca no Catálogo de Teses e Dissertações da Capes, da expressão "prática como componente curricular". Após esse levantamento geral, realizou-se uma seleção das produções que mencionavam, em seu título, as expressões "Ciências Biológicas", "Ciências" e/ou "Biologia". Os dados foram analisados mediante o método de análise de conteúdo, mais especificamente a técnica de análise categorial. Foram encontradas 72 produções, nc período de 2005 a 2019. Destas, apenas 17 correspondiam à área de Ciências Biológicas e apresentaram, como foco principal: organização, desenvolvimento e contribuição da PCC. Para cada um desses enfoques, evidenciaram-se desafios e possibilidades, os quais indicam o que já foi realizado acerca do tema, por exemplo, como a PCC foi inserida nos cursos e as implicações encontradas. Dessa forma, têm-se exemplos que podem ser seguidos, como as diferentes formas de desenvolvimento da PCC e sugestões que podem levar a reflexões e adaptações/transformações. Considera-se, assim, que, por meio desta investigação, foi possível visualizar como está a produção de teses e dissertações acerca da temática PCC, principalmente em relação à área de ensino de Ciências e Biologia, fornecendo um panorama profícuo para novos estudos e implementações da PCC nos currículos de formação de professores.

PALAVRAS-CHAVE: Formação de Professores. Estado do Conhecimento. Ensino de Ciências e Biologia. 


\section{INTRODUÇÃO}

A formação de professores é um importante objeto de pesquisa na área de ensino de ciências. Vários estudos do tipo "estado da arte" apontam que esse tema configura-se entre os mais pesquisados (SCHNETZLER, 2002; SLONGO, 2003; TEIXEIRA; MEGID NETO, 2006). Entretanto, embora haja muitas pesquisas com esse enfoque, há ainda muito a se desvelar, pois, se há críticas ao ensino de forma geral, estas recaem sobre a formação de professores.

Buscando contribuir para o tema, com o olhar voltado à formação inicial de professores, esta proposta emerge. Considerando as várias reformulações já realizadas na tentativa de melhorar essa formação, urge investigar como tais diretrizes têm sido consolidadas. Especificamente, nesta investigação, o olhar está direcionado à prática como componente curricular (PCC), visto que este é um assunto que ainda gera muitas dúvidas, sendo necessário analisar o que tem sido realizado e produzido nesse âmbito e quais as contribuições.

Uma das maneiras de realizar essa sondagem é por meio das produções já realizadas acerca do tema. Portanto, investiga-se quais as áreas têm desenvolvido pesquisas acerca da PCC (teses e dissertações) e quais os apontamentos presentes nas produções da área de ensino de Ciências e Biologia. Assim, dada a importância de discutir e conhecer mais acerca do tema, realizou-se uma ampliação aprofundada do trabalho enviado ao III Simpósio de Pesquisa em Educação para a Ciência, a fim de compor este artigo.

Na sequência, apresentam-se reflexões acerca da formação de professores e a implementação da PCC, a fim de embasar a discussão.

\section{A FORMAÇÃO DE PROFESSORES E A IMPLEMENTAÇÃO DA PRÁTICA COMO COMPONENTE CURRICULAR}

A formação de professores historicamente esteve marcada por conflitos, os quais ainda refletem em questões atuais. Fazendo uma rápida contextualização histórica, essa formação iniciou-se apenas na década de 30, com a criação de Cursos de Licenciatura nas faculdades de Filosofia, visando à atuação desses profissionais na escola secundária. Especificamente, em relação às Ciências Biológicas, a capacitação para lecionar as disciplinas de Ciências, História Natural e Biologia Geral nos colégios e liceus brasileiros ocorria em cursos de Licenciatura em História Natural, no interior das Faculdades de Filosofia, Ciências e Letras (AYRES, 2004; FÁVERO, 1981; LIBÂNEO, 1997).

Nos anos 50, ocorreu uma acelerada industrialização que culminou em grande crescimento econômico, resultando em intensificação da procura pelo ensino, nas décadas de 60-70. Com a falta de professores, houve o impulsionamento da criação das "Licenciaturas Curtas", pelo Conselho Federal de Educação (DUTRA, 2010), sendo que os cursos de Licenciatura Curta em Ciências, continham Física, Química, Biologia, Matemática e Geologia em suas grades curriculares e formavam os professores polivalentes para atuar no 10 grau (Ensino Fundamental - hoje). Já para atuar no 20 grau (Ensino Médio dos dias atuais), os professores realizavam uma complementação por habilitação específica do núcleo comum polivalente por exemplo: Biologia (GOEDERT, 2004). Essa formação aligeirada, segundo 
Fracalanza, Amaral e Gouveia (1986) e Krasilchik (1987), não preparava bem os professores, culminando em deficiências como: pouco conhecimento do conteúdo, falta de formação experimental e dependência do livro didático.

Dutra (2010) salienta que, na década de 60, devido ao aumento do número de faculdades e centros de educação, a formação de professores foi se tornando alvo de estudos. Sendo assim, no final dos anos 70 e na década de 80 , intensas críticas e movimentos reivindicaram mudanças no modelo da racionalidade técnica vigente. Nesse modelo, conforme Pereira (1999, p. 111), o professor é visto como "um técnico, um especialista que aplica com rigor, na sua prática cotidiana, as regras que derivam do conhecimento científico e do conhecimento pedagógico".

Na década de 90 , pesquisas levaram à valorização da formação de professores reflexivos, derivada principalmente dos estudos de Schön. Com a evidência de que o currículo oferecido não era adequado, houve grande mudança na educação brasileira, sendo promulgada a Lei 9.394 - Lei de Diretrizes e Bases da Educação Nacional (LDBEN), que oportuniza que os cursos de licenciatura tenham autonomia na organização dos seus currículos, conforme suas especificidades (DUTRA, 2010), observando as normativas vigentes (BRASIL, 1996). A LDBEN também extinguiu a modalidade de licenciatura curta, devido à formação desqualificada que proporcionava, passando a exigir cursos de Licenciatura Plena (BRASIL, 1996).

Emergida nesse contexto, a formação do professor de Ciências e Biologia foi tardia e baseada na racionalidade técnica, pois constituíram-se de acordo com o modelo de formação conhecido como " $3+1$ " - iniciava-se cursando-se três anos de disciplinas específicas da área a que a formação se referia (por exemplo: Biologia) e, na sequência, realizava-se um ano com disciplinas pedagógicas (GARCIA, 1994).

A partir da década de 80 , os intensos movimentos questionadores que ocorreram resultaram "na adoção do chamado modelo da nova epistemologia da prática (ou da racionalidade prática)" (SÁ; SANTOS, 2009, p. 3). Nesse modelo, “[...] o professor é considerado um profissional autônomo, que reflete, toma decisões e cria durante sua ação pedagógica" e "a prática não é apenas lócus da aplicação de um conhecimento científico e pedagógico, mas espaço de criação e reflexão, em que novos conhecimentos são, constantemente, gerados e modificados" (PEREIRA, 1999, p.113).

Esse contexto, também foi influenciado por estudos acerca dos saberes docentes (TARDIF, 2002; GAUTHIER, 1998), ou seja, aqueles saberes que são próprios dos professores, contribuindo também para a valorização da profissão. Nóvoa (1992, p. 25), nesse sentido, afirma que a formação vai além da acumulação de cursos, pois necessita de "um trabalho de reflexividade crítica sobre as práticas e de (re)construção permanente de uma identidade pessoal".

Portanto, a formação de professores é um processo complexo. Carvalho e GilPérez (1995) discutindo acerca das necessidades formativas dos professores de ciências, indicam, entre elas, que é necessário romper com visões simplistas, como a de que ensinar é fácil. Para isso, os autores advertem que o professor deve conhecer e questionar suas concepções espontâneas, conhecer a matéria a ser ensinada e os estudos teóricos sobre a aprendizagem em Ciências, saber preparar atividades que gerem aprendizagem efetiva e orientar o trabalho dos alunos, saber analisar criticamente o ensino tradicional, saber avaliar e associar docência e pesquisa. 
Perrenoud et al. (2001) corroboram com essa discussão ao afirmar que o professor, caracteriza-se como profissional, pelo domínio de conhecimentos diversos que são inerentes à profissão - conhecimentos ensinados e relativos aos procedimentos de ensino, as posturas necessárias ao ofício, além do conhecimento das próprias representações, o domínio das emoções, a abertura à colaboração e o engajamento profissional.

Nesse cenário, houve um marco em termos de legislação no Brasil, ou seja, a promulgação das resoluções CNE/CP 1 e 2, de 2002, as quais trouxeram novas dimensões para as proposições curriculares dos cursos de licenciaturas, especialmente no que tange à prática de ensino. Antes da promulgação dessas resoluções, "Prática de Ensino era sinônimo de Estágio Supervisionado. Não havia distinção entre ambos" (BIZARRO, 2011, p. 5).

A resolução CNE/CP 2, de 2002, artigo 10, instituiu a carga horária dos cursos de licenciatura, de graduação plena, de no mínimo 2.800 horas, sendo que destas: 400 horas deveriam ser destinadas à prática como componente curricular (PCC), vivenciadas ao longo do curso; e 400 horas ao estágio curricular supervisionado, o qual se iniciava na segunda metade do curso (BRASIL, 2002b).

A resolução em vigor, Resolução CNE/CES 7, de 11 de março de 2002 (BRASIL, 2002c, p. 1), que estabelece as diretrizes curriculares para os cursos de Ciências Biológicas, cita essa mesma resolução de 2002 para a formação de professores, da seguinte forma: "a carga horária da licenciatura deverá cumprir o estabelecido na Resolução CNE/CP 2/2002, resultante do Parecer CNE/CP 28/2001", que estabelece a duração e a carga horária dos cursos de Formação de Professores da Educação Básica, em nível superior, curso de licenciatura e de graduação plena (BRASIL, 2001a).

O Parecer 1.301/2001 (BRASIL, 2001b) traz a redação completa das diretrizes curriculares para os cursos de Ciências Biológicas, na qual indica que o profissional formado nessa área deve "portar-se como educador" (p. 3), logo tanto o bacharel como o licenciado devem ter essa postura. Para a modalidade licenciatura, o parecer também afirma que a formação pedagógica:

[...] deverá contemplar uma visão geral da educação e dos processos formativos dos educandos [...] enfatizar a instrumentação para o ensino de Ciências no nível fundamental e para o ensino da Biologia, no nível médio. [...] [...] serão incluídos, no conjunto dos conteúdos profissionais, os conteúdos da Educação Básica, consideradas as Diretrizes Curriculares Nacionais para a formação de professores em nível superior, bem como as Diretrizes Nacionais para a Educação Básica e para o Ensino Médio (BRASIL, 2001b, p. 6).

Em todos esses aspectos citados, pode-se visualizar a possibilidade de inserção da PCC, pois o trecho sinaliza estudos acerca do ensino, instrumentalização, relação universidade $X$ escola, no que tange aos conteúdos e diretrizes. Indica, ainda, algumas atividades que podem ser realizadas para integrar teoria e prática, como: "monitoria, iniciação científica, apresentação de trabalhos em congressos e seminários, iniciação à docência, cursos e atividades de extensão" (BRASIL, 2001b, p. 6). Claro que, a relação destas instruções com a PCC não é tão simples de ser realizada, pois implica em ampliar a visão acerca de prática.

A introdução das resoluções de 2002 na formação de professores trouxeram essa visão ampliada de prática, que transcende ao estágio, pois a PCC conforme a 
Resolução CNE/CP 1, de 2002, no artigo 12 , contém uma prática que não se restringe somente ao estágio, mas deve estar imbricada dentro das disciplinas, pedagógicas ou não, e presente desde o início do curso (BRASIL, 2002a).

Expressando a distinção a ser considerada, no que diz respeito à prática e ao estágio, essas resoluções desencadearam muitas inquietações nos professores formadores, visto que havia muita dúvida sobre como tornar isso possível. Quanto a essa questão, o artigo 13 da Resolução CNE/CP 1, de 2002, afirma que "em tempo e espaço curricular específico" a PCC deverá ser desenvolvida mediante "ênfase nos procedimentos de observação e reflexão, visando à atuação em situações contextualizadas, com o registro dessas observações realizadas e a resolução de situações-problema". Também enfatiza que "poderá ser enriquecida com tecnologias da informação, incluídos o computador e o vídeo, narrativas orais e escritas de professores, produções de alunos, situações simuladoras e estudo de casos" (BRASIL, 2002a, p. 6).

Outro documento que traz apontamentos de como a prática pode ser desenvolvida é o Parecer CNE/CP no 28/2001 (BRASIL, 2001a, p. 9), o qual ressalta que a PCC é "uma prática que produz algo no âmbito do ensino" e deve ser "uma atividade tão flexível quanto outros pontos de apoio do processo formativo". Logo, a correlação entre teoria e prática se configura como:

[...] um movimento contínuo entre saber e fazer na busca de significados na
gestão, administração e resolução de situações próprias do ambiente da
educação escolar. [...] Pode-se assinalar também uma presença junto a
agências educacionais não escolares [...] entidades de representação
profissional [...]. Importante também é o conhecimento de famílias de
estudantes [...] (BRASIL, 2001a, p. 9).

Esse documento aproxima a PCC da gestão escolar e de outros segmentos da comunidade escolar, incluindo aspectos políticos, administrativos e os pais. Mesmo havendo algumas indicações nesses documentos, essas resoluções são amplas/flexíveis, gerando diferentes interpretações. Assim, em 2005, o último ano dado como prazo para adaptação às novas resoluções, em resposta a uma solicitação de esclarecimento feita pela Universidade Estadual do Sudoeste da Bahia acerca das atividades que deveriam ser desenvolvidas como prática, o Conselho Nacional de Educação (CNE) publicou o parecer denominado "Solicitação de esclarecimento sobre as Resoluções CNE/CP no 1/2002", o qual trouxe alguns esclarecimentos, como a definição de que a "a prática como componente curricular é o conjunto de atividades formativas que proporcionam experiências de aplicação de conhecimentos ou de desenvolvimento de procedimentos próprios ao exercício da docência". Sendo que, "por meio destas atividades, são colocados em uso, no âmbito do ensino, os conhecimentos, as competências e as habilidades adquiridos nas diversas atividades formativas que compõem o currículo do curso" (BRASIL, 2005, p. 3).

Quanto à inclusão da PCC nos cursos, o documento indicou que "podem ser desenvolvidas como núcleo ou como parte de disciplinas ou de outras atividades formativas", incluindo "as disciplinas de caráter prático relacionadas à formação pedagógica, mas não aquelas relacionadas aos fundamentos técnico-científicos correspondentes a uma determinada área do conhecimento". Nesse parecer, ficou claro que "as disciplinas relacionadas com a educação que incluem atividades de caráter prático podem ser computadas na carga horária classificada como 
prática como componente curricular"; todavia, "as disciplinas relacionadas aos conhecimentos técnico-científicos próprios da área do conhecimento para a qual se faz a formação" não entram nessa relação. Acrescentou ainda que "poderão ser criadas novas disciplinas ou adaptadas as já existentes, na medida das necessidades de cada instituição" (BRASIL, 2005, p. 3).

Esse esclarecimento se deu em função de que a palavra "prática" leva a muitas interpretações, e uma delas seria o entendimento de que as aulas práticas já existentes poderiam ser computadas como parte da PCC. Mas, esse documento afirma que apenas as práticas voltadas a aspectos pedagógicos poderiam ser consideradas. Mohr e Cassiani (2017, p. 67) apontam que, principalmente, no curso de Ciências Biológicas "em que há inúmeras práticas de laboratório", é perceptível a confusão acerca do sentido para a palavra "prática". Barbosa e Cassiani (2017), entrevistando professores da área, apontaram que eles apresentam um sentido polissêmico para a PCC, o qual, muitas vezes, relaciona-se a uma prática não educacional, mas técnica, como aula de campo, observação de rochas, atividades comuns na Biologia.

Em 2015, após uma década para o prazo máximo estabelecido para a readequação dos cursos, foi promulgada a Resolução no 2, de 1ㅇ de julho de 2015 (BRASIL, 2015a), a qual trouxe novas Diretrizes Curriculares Nacionais para a formação inicial em nível superior (cursos de licenciatura, cursos de formação pedagógica para graduados e cursos de segunda licenciatura) e para a formação continuada. Nessa resolução, há a ampliação da carga horária mínima dos cursos de formação de professores da educação básica, de no mínimo 2.800 horas para 3.200, sendo: 400 horas destinadas à prática como componente curricular, distribuídas ao longo do processo formativo; 400 horas de estágio supervisionado; pelo menos 2.200 horas de atividades formativas; e 200 horas de atividades teórico-práticas de aprofundamento em áreas específicas de interesse dos estudantes (iniciação científica, iniciação à docência, extensão e monitoria, entre outras).

Em relação à PCC, esse documento não traz adequações, pois mantém a carga horária e a distribuição ao longo do curso. Bego, Oliveira e Corrêa (2017, p. 252), sobre essa resolução, corroboram afirmando que "mantém a PCC com 400 horas e a necessidade de sua distribuição ao longo de todo curso". E apontam que:

[...] o Parecer CNE/CP 2/2015 (Brasil, 2015b) - explicita que a concepção de PCC presente na nova resolução de 2015 é a mesma da Resolução CNE/CP 2/2002 que, por sua vez, fora embasada nos Pareceres CNE/CP 9/2001 e 28/2001 e, posteriormente, esclarecida pelo Parecer CNE/CES 15/2005 (BEGO; OLIVEIRA; CORRÊA, 2017, p. 252).

A declaração aludida pelos autores se dá pois o Parecer CNE/CP 2/2015 (BRASIL, 2015b) cita os trechos referentes à PCC que constam nesses documentos anteriores, os quais foram trazidos neste aporte teórico a fim de elucidar o caminho trilhado pela PCC, desde sua inclusão até atualmente.

Nesse contexto, cita-se ainda o Parecer CNE/CP 22/2019 (BRASIL, 2019a) que justifica e apresenta o projeto de resolução que define as Diretrizes Curriculares Nacionais para a Formação Inicial de Professores para a Educação Básica e institui a Base Nacional Comum para a Formação Inicial de Professores da Educação Básica (BNC-Formação). Esse parecer deu origem à Resolução CNE/CP no 2, de 20 de 
dezembro de 2019, que define atualmente as diretrizes para a formação de professores (BRASIL, 2019b). Quanto à PCC, destaca-se que esta resolução também mantém as 400 horas distribuídas ao longo do curso, situadas agora no que chama de grupo III, composto pelas 800 horas de práticas pedagógicas, sendo as outras 400 destinadas ao estágio supervisionado. Dessa forma, o trecho referente à PCC está descrito conforme segue:

b) 400 (quatrocentas) horas para a prática dos componentes curriculares dos Grupos I e II, distribuídas ao longo do curso, desde o seu início, segundo o PPC ${ }^{1}$ da instituição formadora (BRASIL, 2019b, p. 6).

Os grupos I e II a que o trecho acima se refere, diz respeito à:

I. Grupo I: 800 (oitocentas) horas, para a base comum que compreende os conhecimentos científicos, educacionais e pedagógicos e fundamentam a educação e suas articulações com os sistemas, as escolas e as práticas educacionais.

II. Grupo II: 1.600 (mil e seiscentas) horas, para a aprendizagem dos conteúdos específicos das áreas, componentes, unidades temáticas e objetos de conhecimento da $\mathrm{BNCC}^{2}$, e para o domínio pedagógico desses conteúdos (BRASIL, 2019b, p. 6).

Vale ressaltar que estes três grupos, compõe a carga horária total de, no mínimo, 3.200 horas que todos os cursos em nível superior de licenciatura, destinados à formação inicial de professores para a educação básica, devem ter. Logo, percebe-se que a PCC está atrelada a todos os cursos, como nas resoluções anteriores - por exemplo: Resolução CNE/CP 1, de 2002, a qual afirma que a PCC deve estar presente tanto nas disciplinas pedagógicas como nas específicas (BRASIL, 2002a). O mesmo é ressaltado em um dos princípios norteadores que devem estar presentes na organização curricular dos cursos destinados à formação inicial de professores para a Educação Básica, o qual indica que é necessário reconhecer:

[...] que a formação de professores exige um conjunto de conhecimentos, habilidades, valores e atitudes, que estão inerentemente alicerçados na prática, a qual precisa ir muito além do momento de estágio obrigatório, devendo estar presente, desde o início do curso, tanto nos conteúdos educacionais e pedagógicos quanto nos específicos da área do conhecimento a ser ministrado (BRASIL, 2019b, p. 4);

Do mesmo modo, a resolução também indica que a PCC deve ser articulada ao estágio, como pode ser visualizado no seguinte trecho, referente às habilidades que devem ser desenvolvidas no grupo II: "VI - articulação entre as atividades práticas realizadas na escola e na sala de aula com as que serão efetivadas durante o estágio supervisionado" (BRASIL, 2019b, p. 8).

Embora esses apontamentos discutidos se alinhem, de certo modo, às resoluções e pareceres anteriores já mencionados aqui, a Resolução CNE/CP no 2, de 20 de dezembro de 2019, foi construída tendo por referência a Base Nacional Comum Curricular (BNCC-Educação Básica) (BRASIL, 2017). Logo, este é um aspecto novo, que resultou em muitos questionamentos, pois a BNCC já recebeu críticas de importantes organizações representativas da área educacional como a Associação Nacional de Pós-Graduação e Pesquisa em Educação (ANPED, 2020) e 
a Associação Nacional pela Formação dos Profissionais da Educação (ANFOPE, 2017). Portanto, no que tange a esse aspecto, ainda há muito a discutir e, considerando que o prazo limite é de até dois anos, a partir da publicação da Resolução (BRASIL, 2019b), para a sua implantação, muitas reflexões poderão surgir.

É importante destacar que este não é o foco dessa discussão e por isso apenas cita-se essa questão por estar atrelada ao desenvolvimento da PCC na legislação atual. Entende-se que a PCC, por si só já é um tema que gera muitas indagações e, atrelada aos aspectos da BNCC, poderá ser foco de futuras investigações. Nesta, pretende-se recorrer às pesquisas já realizadas sobre a temática, até $2019^{3}$, a fim de melhor compreendê-las, ao mesmo tempo em que se desvela o que tem sido investigado acerca desse assunto. Assim, constitui-se o foco desta investigação, cujo percurso metodológico apresenta-se na sequência.

\section{PERCURSO METODOLÓGICO}

A presente pesquisa é de natureza qualitativa, a qual, conforme Bogdan e Biklen (1991), tem como características: a coleta de dados diretamente do ambiente natural, sendo o investigador o principal instrumento; a descrição predomina; o significado é o mais importante; é processual e a análise é indutiva.

Esta investigação faz parte da pesquisa de doutorado da primeira autora, cujo enfoque é investigar a PCC em diferentes perspectivas. Inicialmente, realizou-se um estudo do tipo "estado do conhecimento" no "Catálogo de Teses e Dissertações" da Capes, a fim de levantar dados acerca das produções já realizadas sobre a PCC, os quais são discutidos neste trabalho, desvelando o que foi produzido sobre o tema nesse âmbito. Segundo Soares e Maciel (2000), as pesquisas de caráter bibliográfico, do tipo "estado do conhecimento" cujo objetivo é catalogar de forma sistematizada a produção de uma determinada área, são chamadas usualmente também de "estado da arte". Porém, nesta análise optou-se pela denominação de "estado do conhecimento", baseado em Romanowski e Ens (2006, p. 40) que afirmam: "o estudo que aborda apenas um setor das publicações sobre o tema estudado vem sendo denominado de 'estado do conhecimento'". Logo, esta investigação pode ser caracterizada dessa forma, uma vez que, o corpus analisado é composto por teses e dissertações. Morosini e Fernandes (2014, p. 155), pontuam que este tipo de pesquisa traz "identificação, registro, categorização que [...]" levam "[...] à reflexão e síntese sobre a produção científica de uma determinada área, em um determinado espaço de tempo". Para Soares e Maciel (2000, p. 9) a importância de estudos desse tipo está em contribuir "à plena compreensão do estado atingido pelo conhecimento a respeito de determinado tema - sua amplitude, tendências teóricas, vertentes metodológicas". Possibilitando "identificar duplicações, contradições e, sobretudo, lacunas, isto é, aspectos não estudados ou ainda precariamente estudados" (SOARES; MACIEL, 2000, p. 6).

Nesta investigação, a coleta no catálogo deu-se por meio da inserção no campo de busca das seguintes palavras-chaves: "prática como componente curricular" (entre aspas, assim como demonstrado - para que fossem buscadas juntas, pois quando soltas, evidenciavam trabalhos fora do contexto, conforme verificado antes). Essa busca ocorreu no título, resumo ou palavra-chave das 
produções. Em relação ao tempo, o período encontrado foi de 14 anos, iniciandose em 2005 até 2019, quando a busca foi encerrada. Consideraram-se, para visualização geral, todas as produções evidenciadas. Após esse levantamento, filtrou-se a busca para identificar apenas as pesquisas que envolviam a área de Ciências Biológicas, sendo que, para isso, foram considerados apenas os trabalhos que continham, como parte de seus títulos, as palavras: "Ciências Biológicas"; "Ciências" e/ou "Biologia"".

Esse tipo de análise pode ser característica de uma pesquisa documental, pois "é aquela realizada a partir de documentos, contemporâneos ou retrospectivos" (PÁDUA, 1997, p. 62) e apresenta vantagens que foram aproveitadas: os "documentos constituem fonte rica e estável de dados" (GIL, 2002, p. 46), o custo é baixo, não há necessidade de contato com os sujeitos da pesquisa e é possível aprofundar o olhar acerca das fontes.

Após a busca pelas produções da área de Ciências Biológicas, foi realizada uma análise detal hada e os dados foram submetidos ao método de análise de conteúdo de Bardin (2000). Esse método compreende um conjunto de técnicas de análise de comunicações que objetiva elencar indicadores, de forma sistemática e objetiva, os quais permitam a inferência de conhecimentos quanto às condições de produção e/ou recepção dessas mensagens, por meio da interpretação. Neste trabalho, foi utilizada a técnica de análise categorial, que se constitui das seguintes etapas: pré-análise (realização de leitura flutuante, evidenciando as primeiras impressões); exploração do material (recorte, agregação e enumeração dos dados brutos, estabelecendo representações do conteúdo); categorização (classificação dos dados); tratamento dos resultados, inferência e interpretação (apresentação dos dados categorizados por meio de um texto, no qual está presente proposição de variáveis que indicam o que conduziu a um determinado enunciado e quais as consequências que este pode provocar, assim como a construção de significações às características extraídas do texto).

Assim, a seguir apresenta-se a discussão dos resultados desse processo metodológico.

\section{RESULTADOS E DISCUSSÕES}

A produção de teses e dissertações acerca da PCC não é abundante, pois mesmo investigando inicialmente apenas o tema em si, sem especificar a área de Ciências Biológicas (foco da pesquisa), não foram evidenciadas muitas investigações. Identificaram-se apenas 72 produções, sendo que destas, somente 17 referiam-se à área de Ciências Biológicas.

Esse número corrobora com os dados de Tolentino (2017), que realizou uma investigação semelhante, nas atas do ENPEC e do ENEBIO, no período de 2005 a 2015, e evidenciou que no ENPEC, de 5.656 trabalhos, apenas 21 envolviam a PCC. Nas atas do ENEBIO, a autora encontrou 10 trabalhos, de um total de 1.818, sinalizando que há uma inexpressão de artigos envolvendo essa temática.

Após esse levantamento inicial, realizou-se uma análise mais aprofundada nas produções envolvendo a área de Ciências Biológicas. Portanto, serão apresentados esses trabalhos, identificando título, autor, ano e campo de estudo, no quadro 1 a seguir: 
Quadro 1 - Identificação das produções envolvendo a PCC na área de Ciências Biológicas

\begin{tabular}{|c|c|c|c|c|}
\hline Sigla & Título & Autor & Ano & $\begin{array}{c}\text { Campo de } \\
\text { estudo }\end{array}$ \\
\hline D1 & $\begin{array}{l}\text { A contextualização no âmbito da } \\
\text { prática como componente } \\
\text { curricular de genética }\end{array}$ & $\begin{array}{l}\text { César } \\
\text { Henrique } \\
\text { Pinto } \\
\text { Moreira }\end{array}$ & 2017 & $\begin{array}{l}\text { Uma Instituição } \\
\text { de ensino } \\
\text { superior de } \\
\text { Pernambuco }\end{array}$ \\
\hline D2 & $\begin{array}{c}\text { Configurações da prática como } \\
\text { componente curricular nos cursos } \\
\text { de licenciatura em Ciências } \\
\text { Biológicas de universidades } \\
\text { públicas em Goiás: sentidos e } \\
\text { implicações }\end{array}$ & $\begin{array}{l}\text { José Firmino } \\
\text { de Oliveira } \\
\text { Neto }\end{array}$ & 2016 & $\begin{array}{l}\text { Universidade } \\
\text { Estadual de } \\
\text { Goiás e } \\
\text { Universidade } \\
\text { Federal de } \\
\text { Goiás }\end{array}$ \\
\hline D3 & $\begin{array}{l}\text { Iniciando a docência: a construção } \\
\text { do perfil profissional na visão dos } \\
\text { futuros professores de ciências da } \\
\text { UFPEL }\end{array}$ & $\begin{array}{l}\text { Caciele } \\
\text { Guerch } \\
\text { Gindri de } \\
\text { Bastos }\end{array}$ & 2015 & $\begin{array}{l}\text { Universidade } \\
\text { Federal de } \\
\text { Pelotas }\end{array}$ \\
\hline D4 & $\begin{array}{l}\text { A prática como componente } \\
\text { curricular na formação de } \\
\text { professores do curso de } \\
\text { licenciatura em Biologia do IFPI } \\
\text { campus Floriano }\end{array}$ & $\begin{array}{l}\text { Francisca } \\
\text { Ocilma } \\
\text { Mendes } \\
\text { Monteiro }\end{array}$ & 2013 & $\begin{array}{l}\text { Instituto } \\
\text { Federal do } \\
\text { Piauí - campus } \\
\text { Floriano }\end{array}$ \\
\hline D5 & $\begin{array}{l}\text { A prática como componente } \\
\text { curricular na formação do } \\
\text { professor de Biologia: } \\
\text { contribuições? }\end{array}$ & $\begin{array}{l}\text { Alessandra } \\
\text { Maria } \\
\text { Pereira } \\
\text { Martins da } \\
\quad \text { Silva }\end{array}$ & 2014 & $\begin{array}{l}\text { Universidade } \\
\text { Federal Rural } \\
\text { de Pernambuco }\end{array}$ \\
\hline D6 & $\begin{array}{c}\text { Sentidos da prática como } \\
\text { componente curricular na } \\
\text { licenciatura em Ciências Biológicas }\end{array}$ & $\begin{array}{l}\text { Alessandro } \\
\text { Tomaz } \\
\text { Barbosa }\end{array}$ & 2015 & $\begin{array}{l}\text { Universidades } \\
\text { federais da } \\
\text { Paraíba e } \\
\text { Universidade } \\
\text { Federal de } \\
\text { Campina } \\
\text { Grande }\end{array}$ \\
\hline D7 & $\begin{array}{l}\text { A prática pedagógica como } \\
\text { componente curricular na } \\
\text { formação de professores: a visão } \\
\text { de graduandos do curso de } \\
\text { Ciências Biológicas (diurno) da } \\
\text { Universidade Federal de Santa } \\
\text { Catarina }\end{array}$ & $\begin{array}{l}\text { Elisa } \\
\text { Margarita } \\
\text { Orlandi }\end{array}$ & 2015 & $\begin{array}{l}\text { Universidade } \\
\text { Federal de } \\
\text { Santa Catarina }\end{array}$ \\
\hline D8 & $\begin{array}{c}\text { Entre concepções e desafios: a } \\
\text { prática pedagógica como } \\
\text { componente curricular na } \\
\text { perspectiva de professores } \\
\text { universitários de Ciências } \\
\text { Biológicas }\end{array}$ & $\begin{array}{l}\text { Beatriz } \\
\text { Pereira }\end{array}$ & 2016 & $\begin{array}{l}\text { Universidade } \\
\text { Federal de } \\
\text { Santa Catarina }\end{array}$ \\
\hline D9 & $\begin{array}{l}\text { Prática como componente } \\
\text { curricular - definições legais e sua } \\
\text { expressão na formação inicial do } \\
\text { professor de Ciências e Biologia }\end{array}$ & $\begin{array}{l}\text { Aline Bona } \\
\text { Omelczuk }\end{array}$ & 2017 & $\begin{array}{l}\text { Universidade } \\
\text { Federal de } \\
\text { Santa Maria - } \\
\text { Campus Santa } \\
\quad \text { Maria }\end{array}$ \\
\hline
\end{tabular}




\begin{tabular}{|c|c|c|c|c|}
\hline Sigla & Título & Autor & Ano & $\begin{array}{l}\text { Campo de } \\
\text { estudo }\end{array}$ \\
\hline D10 & $\begin{array}{l}\text { Jogos didáticos na formação inicial } \\
\text { de professores de Biologia }\end{array}$ & $\begin{array}{c}\text { Renata } \\
\text { Rolins da } \\
\text { Silva Oliveira }\end{array}$ & 2016 & $\begin{array}{l}\text { Instituto } \\
\text { Federal de } \\
\text { Ciência e } \\
\text { Tecnologia } \\
\text { Goiano - } \\
\text { Campus Ceres }\end{array}$ \\
\hline T1 & $\begin{array}{l}\text { Hibridismo epistemológico e } \\
\text { formativo na licenciatura em } \\
\text { Ciências Biológicas: como os } \\
\text { docentes de disciplinas específicas } \\
\text { se implicam na articulação da } \\
\text { formação inicial com a prática } \\
\text { profissional }\end{array}$ & $\begin{array}{l}\text { Ana Verena } \\
\text { Magalhães } \\
\text { Madeira }\end{array}$ & 2014 & $\begin{array}{l}\text { União } \\
\text { Metropolitana } \\
\text { de Educação e } \\
\text { Cultura e } \\
\text { Universidade } \\
\text { Estadual de } \\
\text { Feira de } \\
\text { Santana }\end{array}$ \\
\hline T2 & $\begin{array}{l}\text { Constituição da identidade } \\
\text { profissional docente dos } \\
\text { formadores de professores de } \\
\text { Biologia: potencialidades da } \\
\text { intercoletividade }\end{array}$ & $\begin{array}{l}\text { Marilisa } \\
\text { Bialvo } \\
\text { Hoffmann }\end{array}$ & 2016 & $\begin{array}{l}\text { Universidade } \\
\text { Federal da } \\
\text { Fronteira Sul } \\
\text { campus } \\
\text { Realeza-PR }\end{array}$ \\
\hline T3 & $\begin{array}{l}\text { Os estudos Ciência, Tecnologia e } \\
\text { Sociedade e a prática como } \\
\text { componente curricular: tensões, } \\
\text { desafios e possibilidades na } \\
\text { formação de professores nas } \\
\text { Ciências Biológicas }\end{array}$ & $\begin{array}{l}\text { Patricia } \\
\text { Caldeira } \\
\text { Tolentino }\end{array}$ & 2017 & $\begin{array}{l}\text { Universidade } \\
\text { Estadual de } \\
\text { Ponta Grossa }\end{array}$ \\
\hline T4 & $\begin{array}{c}\text { As práticas pedagógicas e os } \\
\text { saberes da docência na formação } \\
\text { acadêmico-profissional em Ciências } \\
\text { Biológicas }\end{array}$ & $\begin{array}{l}\text { Lucio Ely } \\
\text { Ribeiro } \\
\text { Silvério }\end{array}$ & 2014 & $\begin{array}{l}\text { Universidade } \\
\text { Federal de } \\
\text { Santa Catarina }\end{array}$ \\
\hline T5 & $\begin{array}{l}\text { Construção de relações teoria- } \\
\text { prática na formação de professores } \\
\text { de Ciências e Biologia }\end{array}$ & $\begin{array}{l}\text { Gabriel } \\
\text { Menezes } \\
\text { Viana }\end{array}$ & 2014 & $\begin{array}{l}\text { Uma grande } \\
\text { Universidade } \\
\text { do Sudeste } \\
\text { Brasileiro }\end{array}$ \\
\hline T6 & $\begin{array}{c}\text { A configuração da "prática como } \\
\text { componente curricular" nos cursos } \\
\text { de licenciatura em Ciências } \\
\text { Biológicas das Universidades } \\
\text { Estaduais da Bahia }\end{array}$ & $\begin{array}{l}\text { Luisa Dias } \\
\quad \text { Brito }\end{array}$ & 2011 & $\begin{array}{l}\text { Universidades } \\
\text { estaduais da } \\
\text { Bahia }\end{array}$ \\
\hline T7 & $\begin{array}{c}\text { Demandas e dilemas da prática } \\
\text { como componente curricular na } \\
\text { formação de professores de } \\
\text { Biologia }\end{array}$ & $\begin{array}{l}\text { Jaiane de } \\
\text { Moraes } \\
\text { Boton }\end{array}$ & 2019 & $\begin{array}{c}\text { Treze } \\
\text { diferentes } \\
\text { instituições do } \\
\text { Brasil - } \\
\text { públicas e } \\
\text { privadas }\end{array}$ \\
\hline
\end{tabular}

Fonte: Autoria própria (2020).

No quadro 1, verifica-se, que, do total de 17 produções na área de Ciências Biológicas, obtiveram-se 10 dissertações (D1 a D10) e 7 teses (T1 a T7), produzidas a partir de 2011, ou seja, nos últimos nove anos. As dissertações concentram-se de 2013 até 2017, tendo pelo menos uma produção por ano e um número maior em 2015 (3). Quanto às teses, embora em número menor, observa-se a primeira produção em 2011, ou seja, um pouco antes das dissertações; porém, com 
intervalos sem trabalhos, pois as próximas são de 2014 (ano com maior quantidade- 3), seguido de 2016, 2017 e 2019 (apenas um por ano). Conforme Saviani $(2010, \mathrm{~s} / \mathrm{p})$, "a experiência universitária no Brasil é bastante recente"; consequentemente, os programas de pós-graduação também o são. Acrescentase a isso o tempo da produção de uma tese, justificando o baixo número de produções, visto que a PCC foi implementada em 2002 e as investigações acerca do tema iniciaram-se somente alguns anos depois.

Para categorizar o enfoque dado pelos autores nessas produções, buscou-se por temas semelhantes e, embora a princípio as unidades de análise encontradas parecessem discrepantes, foi possível, com uma análise mais aprofundada, identificar três enfoques principais, conforme apresenta-se no quadro a seguir:

Quadro 2 - Enfoques das pesquisas envolvendo a PCC em Ciências Biológicas

\begin{tabular}{|c|c|c|c|c|}
\hline $\begin{array}{l}\text { Enfoque das } \\
\text { pesquisas em } \\
\text { relação à PCC }\end{array}$ & Unidades de análise & $\begin{array}{c}\text { Dissertações } \\
\text { (Anos) }\end{array}$ & $\begin{array}{l}\text { Teses } \\
\text { (Anos) }\end{array}$ & Total \\
\hline Organização & $\begin{array}{c}\text { "Configurações"; } \\
\text { "Delineamento"; “Definição"; } \\
\text { "Caracterização" }\end{array}$ & - & $\begin{array}{c}\text { T6 } \\
\text { (2011) }\end{array}$ & 1 \\
\hline Desenvolvimento & $\begin{array}{l}\text { "Contextualização"; “Sentidos } \\
\text { da PCC"; “Objetivo da PCC”; } \\
\text { “Engajamento"; “Inserção”; } \\
\text { "Práticas Pedagógicas"; } \\
\text { “Desenvolvimento"; } \\
\text { "Estratégia"; “Processos de } \\
\text { Construção"; “Visão" }\end{array}$ & $\begin{array}{l}\text { D1, D8, D10 } \\
\text { (2017, } 2016- \\
2 \text { últimas) }\end{array}$ & $\begin{array}{c}\text { T1, T4, } \\
\text { T5 } \\
\text { (2014 - } \\
\text { todas) }\end{array}$ & 6 \\
\hline Contribuição & $\begin{array}{l}\text { "Perfil docente"; } \\
\text { "Contribuições"; } \\
\text { "Intercoletividade" }\end{array}$ & $\begin{array}{l}\text { D3, D7 } \\
\text { (2015- } \\
\text { ambas) }\end{array}$ & $\begin{array}{c}\text { T2 } \\
(2016)\end{array}$ & 3 \\
\hline $\begin{array}{c}\text { Organização e } \\
\text { desenvolvimento }\end{array}$ & $\begin{array}{l}\text { As mesmas citadas } \\
\text { individualmente }\end{array}$ & $\begin{array}{c}\text { D2, D6, D9 } \\
(2016,2015 \\
2017) \\
\end{array}$ & $\begin{array}{l}\text { T3, T7 } \\
(2017 \\
2019) \\
\end{array}$ & 5 \\
\hline $\begin{array}{l}\text { Organização e } \\
\text { contribuição }\end{array}$ & $\begin{array}{l}\text { As mesmas citadas } \\
\text { individualmente }\end{array}$ & $\begin{array}{c}\text { D4, D5 } \\
(2013,2014) \\
\end{array}$ & - & 2 \\
\hline Total & - & 10 & 7 & 17 \\
\hline
\end{tabular}

Fonte: Autoria própria (2020).

Como pode ser notado no quadro 2, a preocupação com a organização dos cursos de Ciências Biológicas-Licenciatura sempre esteve presente, desde 2011 até 2019, e em 8 trabalhos; incluindo os concomitantes, ou seja, aqueles que investigaram a organização juntamente com outro aspecto (desenvolvimento, contribuição ou ambos). Pereira e Mohr (2017, p. 35) afirmam que "formular como esse componente curricular pode se materializar nos currículos é, atualmente, talvez, um dos grandes desafios dos cursos de formação de professores". Nessa direção, Oliveira (2014) aponta que tem sido um desafio implementar a PCC nos cursos de licenciatura e os dados encontrados corroboram com essas afirmações. Madeira $(2014$, p. 93) aponta que muitos professores do curso têm uma formação inicial "forjada em uma cultura tecnicista e positivista", e quando, por exigências curriculares necessitam apresentar "uma prática profissional docente na qual são demandadas ações e atitudes formativas", passam por tensões e contradições. 
O modo como a PCC está sendo desenvolvida demonstra que essa temática é considerada relevante atualmente, pois, considerando-se os concomitantes, apresenta o maior número de trabalhos (11) e envolve apenas os últimos anos. Esse crescente número de produções é significativo, dada a indicação de que, infelizmente, "a PCC muitas vezes é compreendida de maneira distorcida, sendo confundida com a aplicação dos conhecimentos específicos da matéria de ensino em sala de aula [...] com Estágio Curricular Supervisionado ou com técnicas de práticas em laboratório" (BOTON; TOLENTINO-NETO, 2019, p. 127). Portanto, pesquisas com esse enfoque podem contribuir para a mudança dessa compreensão.

Os estudos relacionados à contribuição (cinco trabalhos, incluindo os concomitantes) podem ser vistos como uma temática ainda um pouco tímida, mas que indica crescimento, pois inicia-se em 2013 e apresenta mais trabalhos atualmente (2015 e 2016).

Pode-se inferir que, no início, a preocupação em relação à PCC estava voltada à sua organização no currículo. Preocupação que ainda permanece, levando a se conjecturar que ainda não existe uma definição clara de qual a configuração adequada. Brito (2011) verificou que há diferentes possibilidades de interpretações, assim como disputas de interesses envolvidas no processo de implantação da PCC; logo, ocorrem distintas recontextualizações.

Questionar qual a contribuição da inserção da PCC para a formação só aparece nos trabalhos mais recentes, assim como em relação ao modo como está sendo desenvolvida. A demora em investigar a primeira temática é compreensível, se considerar que os cursos demoram quatro anos, no mínimo, para formar um aluno. Logo, como os cursos tinham até 2005 para se adequar às primeiras resoluções acerca da PCC, apenas em 2009 estariam formados os alunos dos últimos cursos que se adequaram. Considerando novamente que uma dissertação leva dois anos para ser concluída, apenas em 2011 se poderia ter o primeiro trabalho, mas este aparece somente em 2013, demonstrando que o interesse pelo tema demorou um pouco mais. Em relação ao desenvolvimento da PCC, apenas recentemente essa temática é enfocada (início 2014), porém, já desponta como a temática mais investigada, podendo-se inferir que há um interesse acentuado em relação ao que tem sido realizado como PCC.

Considerando-se esse panorama geral, necessita-se apresentar um olhar mais específico. Sendo assim, quanto às produções que investigaram a organização da PCC, todas (8) envolveram a análise de PPP de curso/s de Ciências BiológicasLicenciatura. Destas, cinco envolveram mais que um curso. A saber, foram investigados os cursos das Universidades Estaduais da Bahia (T6), das Universidades Estaduais do Paraná (T3), das Universidades Federais da Paraíba (D6), da universidade estadual de Goiás juntamente com o da Universidade Federal de Goiás (D2) e de mais 13 instituições de ensino superior do país - públicas e privadas (T7). Outras três produções envolveram, respectivamente, apenas um curso, sendo estes da Universidade Federal Rural de Pernambuco (D5), da Universidade Federal de Santa Maria (D9) e do Instituto Federal do Piauí (D4). Analisar o PPP de um curso é visualizar o perfil planejado, pois permite identificar os diferentes lugares em que a PCC está presente, apontando para uma formação mais tecnicista ou formativa (SILVÉRIO, 2017; TORRES, 2017). 
Ainda nesse enfoque, duas produções preocuparam-se também com a análise das legislações que regem a PCC (T3; D9). Em uma delas, foi realizada, concomitantemente, uma análise das atas do ENPEC e ENEBIO (T3), e, em outra, uma análise dos planos de ensino das disciplinas (D5). A análise das legislações é importante, uma vez que é a principal fonte para o estabelecimento dos cursos. Mohr e Wielewicki (2017, s/p) argumentam, em relação à PCC, que é necessário "compreender seus fundamentos e objetivos para que a partir de cada contexto se possa executar diferentes soluções curriculares". Os estudos do tipo "estado da arte" permitem conhecer o que já foi produzido, a fim de saber como avançar. Por último citada, a análise dos planos de ensino é um olhar mais aprofundado para os documentos de um curso, pois já se trata do planejamento específico dos professores para a disciplina pela qual são responsáveis. Quanto à questão de planejar, "é preciso que os professores assumam a consciência da centralidade das atividades de PCC em seu planejamento estratégico, bem como da relevância de suas disciplinas no processo de formação inicial docente" (TORRES; SILVÉRIO; MAESTRELLI, 2017, p. 238).

Os resultados das produções que envolveram a organização da PCC remetem a desafios e possibilidades. Quanto às possibilidades: três produções apontaram que os cursos cumprem as 400 horas de carga horária (D2; D4; D5), conforme a resolução CNE/CP 2 de 2002 (BRASIL, 2002b, s/p); duas apontam que há a relação teoria e prática nos PPP (D2; D4); e, apenas citada em uma delas, tem-se que a inserção da PCC aproxima universidade e escola de educação básica (D4) e permite uma abordagem ligada à interdisciplinaridade (D2). Nesse contexto, Viana e Coutinho $(2017$, p. 258) visualizaram que a presença da PCC no currículo de um curso "provoca uma necessidade de adequação de disciplinas acadêmicas e da relação entre a universidade e a escola. Assim como atua como um organizador e estruturador do currículo".

Os desafios foram mencionados de forma diferente em cada produção: o PPP apenas cita a importância de articular teoria e prática, mas não menciona como desenvolver essa relação (D9); nem todos os cursos cumprem as normativas legais (T6 e T7); as aproximações com um fazer e saber prático são ausentes (D2); há a necessidade de inserir aspectos humanos, políticos e sociais (CTS) nas atividades ligadas à PCC (T3); a legislação aponta a obrigatoriedade do estreitamento da relação teoria e prática ao longo do curso, porém não indica claramente como isso deve ser trabalhado/desenvolvido (D9); há predominância de disciplinas específicas da matéria de ensino em relação às pedagógicas (T7). A falta de uma especificidade maior em relação à PCC apontada nessas produções é reflexo da própria legislação no que tange a como desenvolvê-la, pois, conforme afirmam Pereira e Mohr (2017, p. 35), "as legislações [...] tentam esclarecer o papel da prática ao longo do currículo, seu objetivo e em quais momentos ela pode ocorrer. Contudo, [...] não fornece exemplos ou menciona atividades específicas que poderiam ser realizadas para desenvolver a PCC".

Em relação às produções que envolveram o desenvolvimento da PCC, foram identificados quatro enfoques: documentos oficiais (envolveu análise de PPP, legislação, análise de relatório de reforma curricular) (D2; D6; D9; T4; T7); enfoque da disciplina (análise de atividades, observação de aulas/reuniões, observação participante, materiais produzidos na e para a disciplina, gravação de aulas) (D1; T5); percepções de professores universitários e da educação básica (questionários, 
entrevistas e memorial de formação) (T1; D6; D8; T3; T4; T7); percepções de licenciandos (questionário, entrevistas e grupo focal) (D6; D10; T3; T7).

Nos resultados dessas produções, igualmente foram evidenciados desafios e possibilidades. As possibilidades dizem respeito a: inserção da PCC mobiliza experiências vivenciadas e imaginadas pelos licenciandos (T5), bem como espaço e contato com o real e a formação de professores reflexivos (D2) ; elaboração de jogos é uma estratégia vantajosa para o desenvolvimento da PCC (D10); transposição didática possibilita a relação teoria e prática (D2; D9); interdisciplinaridade favorece a PCC (D2); aproximar CTS e PCC pode contribuir para a construção da prática pedagógica crítica e reflexiva (T3); há diferentes maneiras de trabalhar a PCC e incluí-la no curso (T7). Embora esses resultados sejam promissores, os desafios são igualmente provocadores: os processos de relação teoria e prática são complexos; há desconhecimento do que é a PCC (T7); pluralidade de concepções de prática (D6; T7), dúvidas quanto ao papel da PCC, bem como diferentes interpretações da legislação, o que implica em um efeito dominó em relação ao que é realizado em sala de aula (D6); há necessidade de evidenciar melhor a articulação entre as disciplinas específicas e pedagógicas e a concepção de prática adotada no curso (D6; T4), assim como é necessário fortalecer parcerias entre universidade e escola e, renovar os cursos visando a preservar a característica própria da licenciatura (T7).

A contextualização (D1) e o desenvolvimento de materiais didáticos (D8), embora sejam apontados como possibilidade de desenvolvimento da PCC, apresentam desafios, pois, conforme os autores, a contextualização nem sempre ocorre da forma indicada pela literatura, e, quanto aos materiais didáticos, evidenciou-se que o objetivo de os produzir contém uma hibridização de concepção entre racionalidade técnica e prática. Essa hibridização também ocorre na identificação dos professores de áreas específicas com a formação da licenciatura, ou seja, há uma hibridização epistemológica e formativa que os envolve (T1), indicando, portanto, a necessidade de formação desses professores para atuar nos cursos de licenciatura, embora revelem preocupação quanto à formação de futuros professores (T7).

Quanto à contribuição da PCC para a formação de licenciandos, cinco produções investigaram o tema a partir dos seguintes métodos: entrevistas com professores (D4; D5; T2), grupo focal com licenciandos (D4; D7), entrevistas com licenciandos (D7), questionários com licenciandos (D5) e observação não participante da prática pedagógica no ensino de Ciências (D3). Os resultados indicam percepções de professores e licenciandos, sendo que as dos professores apontam elementos para que a intercoletividade na docência no Ensino Superior possa ser efetivada (T2); alguns enfatizam tanto o conhecimento teórico quanto o prático do conteúdo pedagógico, outros enfatizam a teoria do conhecimento, seja específico ou pedagógico (D5). As percepções dos licenciandos indicam que a PCC promove a reflexão, sensibiliza para as questões da educação, é um momento de aprendizado para futuras situações pedagógicas, é um espaço para a construção dos saberes docentes (D7); apontam que os professores enfatizam tanto o conhecimento teórico quanto prático do conteúdo específico e pedagógico; consideram que as disciplinas específicas e pedagógicas cumprem seu papel (D3). Os licenciandos sugerem ainda a inserção de mais práticas no decorrer do curso, mais articulação entre disciplinas específicas e pedagógicas, mais preparo para o 
ensino de Ciências e maior proximidade entre universidade e escola (D3). Professores e licenciandos ainda concordam que as atividades ligadas à PCC buscam relacionar teoria e prática, aproximam universidade e escola e qualificam a formação inicial docente (D4). Silvério (2014, p. 61) tecendo algumas considerações acerca dessa aproximação entre universidade e escola, assim como acerca da relação teoria e prática, afirma que "uma formação impregnada pela prática como componente curricular, desde o começo do curso, pode auxiliar o futuro professor a se aproximar do ambiente educativo e do contexto escolar concreto". Mas adverte que, para a PCC "se constituir a partir de experiências significativas de integração teoria-prática na formação, ela precisa ser concebida a partir de uma organização curricular que ajude a superar a visão aplicacionista da teoria e a visão ativista da prática".

Essas considerações sinalizam a relação que há entre a percepção da PCC e sua implantação. Calixto e Kiouranis $(2017$, p. 9) destacam a necessidade de "avaliações e reflexões sobre o lugar e o significado da PCC no currículo, por meio de componentes exclusivos e mistos, permeados por conceitos que intensifiquem a indissociabilidade entre o fazer e o pensar na ação docente".

Portanto, este estudo do estado da arte da PCC nas dissertações e teses sinaliza que, embora em um número pouco expressivo, as produções relacionadas à área de Ciências têm discutido esses aspectos.

Mohr e WieleWicki (2017, s/p.) apontam que, embora haja "múltiplas compreensões e formatos para a PCC [...] não significa que tudo é possível." Por isso, estudos como este podem contribuir para melhor compreensão do tema e do que se tem realizado acerca dele. Ainda, conforme os autores, "há que compreender seus fundamentos e objetivos para que a partir de cada contexto se possa executar diferentes soluções curriculares. O que não é desejável ou admissível é nem bem entendermos a PCC e já estarmos a reformá-la...".

\section{CONSIDERAÇÕES FINAIS}

A produção de teses e dissertações envolvendo a PCC ainda é pequena, pois foram encontradas apenas 72 investigações em 14 anos. Na área de Ciências Biológicas, o número é ainda mais inexpressivo: apenas 17 pesquisas em 9 anos.

Destas, o enfoque das produções deu-se em torno de três eixos: organização, desenvolvimento e contribuição da PCC, sendo que organização foi o enfoque mais presente, desde o início das pesquisas, acerca do tema, até atualmente. Porém, não foi o enfoque mais pesquisado, pois este se deu em torno do desenvolvimento da PCC, e, embora as produções tenham sido evidenciadas mais recentemente, é o tema com maior número de trabalhos. Por último, tem-se o enfoque "contribuição", ainda um pouco tímido, mas com crescente interesse nos últimos anos.

As produções acerca da organização da PCC envolveram principalmente os PPP dos cursos de Ciências Biológicas, e evidenciaram que nem todas as universidades haviam se adequado à quantidade de horas. Por outro lado, mesmo nos PPP em que a PCC estava presente, não havia indicações de como desenvolvêla. 
Em relação ao enfoque "desenvolvimento", os dados evidenciaram meios de promover a PCC, como: elaboração de jogos, transposição didática, interdisciplinaridade, contextualização e trabalho na perspectiva Ciência/Tecnologia/Sociedade. Os desafios em relação a esse enfoque demonstram que a promoção da relação teoria e prática ainda é um processo complexo, pois há pluralidade de concepções de prática, que podem ser relacionadas, entre outros aspectos, a diferentes interpretações da legislação e à hibridização de concepção entre racionalidade técnica e prática que há na formação dos professores formadores.

Quanto à contribuição da PCC, os dados demonstraram que possibilita intercoletividade no Ensino Superior, reflexão, relação teoria e prática, aproximação de universidade e escola, sensibilização para as questões da educação, construção dos saberes docentes, qualificando a formação inicial. Há, ainda, sugestões de inserção de mais práticas no decorrer do curso, mais articulação entre disciplinas específicas e pedagógicas, mais preparo para o ensino de Ciências e maior proximidade entre universidade e escola.

Considera-se, assim, que por meio desta investigação foi possível mapear como está a produção de teses e dissertações acerca da temática PCC, e os resultados evidenciaram desafios e possibilidades. As possibilidades sinalizam exemplos do que pode ser realizado e quais as contribuições identificadas. Os desafios indicam elementos sobre os quais é necessário refletir e buscar formas de superá-los.

Assim, espera-se, com este estudo, contribuir para reflexões acerca da implementação da PCC nos cursos de licenciatura, visto que os currículos não são fixos, havendo sempre possibilidade de novas adequações ou transformações. 


\title{
Practice as a curricular component in biological sciences teachers' training: what do theses and dissertations disclose?
}

\begin{abstract}
Teacher's background is an important object to be studied in Science education area. However, practice as a curricular component (PCC) is a topic that still raises many doubts among teachers' educators. Thus, this paper aimed at quantifying - theses and dissertations - productions regarding PCC theme and also investigating which notes are present in the productions of Science and Biology teaching area. So, a documentary research was carried out by searching the Capes Thesis and Dissertations Catalog, using the expression "practice as a curricular component". After this general survey, a selection was made regarding the productions that mentioned, in their title, the expressions "Biological Sciences", "Sciences" and / or "Biology". Data were analyzed using the content analysis method, specifically the categorical analysis technique. 72 productions were registered from 2005 to 2019. And, based on these ones, only 17 corresponded to the Biological Sciences area, and presented as main focus: organization, development and contribution of the PCC. For each of these approaches, challenges and possibilities were evidenced, which have indicated what has already been accomplished on this area, for example, how PCC was introduced in the courses and which implications were obtained. Consequently, there are examples that can be followed, such as the different ways of PCC development and suggestions that can lead to reflections and adaptations/transformations. At last, it is considered that, according to this investigation, it was possible to visualize how the production of theses and dissertations regarding PCC theme is, mainly in relation to the Science and Biology teaching area, providing a fruitful panorama for new studies and PCC accomplishment in teachers' training curricula.
\end{abstract}

KEYWORDS: Teachers' Background. State of Knowledge. Science and Biology Teaching. 


\section{NOTAS}

${ }^{1}$ Sigla utilizada no documento para: Projeto Pedagógico do Curso.

${ }^{2}$ Sigla utilizada no documento para: Base Nacional Comum Curricular.

${ }^{3}$ Como a resolução baseada na BNCC foi promulgada no final do ano de 2019, as produções que fazem parte dos dados coletados ainda não a mencionam.

${ }^{4}$ Com exceção de uma produção que contém a palavra "genética" no título, mas foi considerada por ser uma subárea da Biologia.

\section{REFERÊNCIAS}

ASSOCIAÇÃO NACIONAL PELA FORMAÇÃO DOS PROFISSIONAIS DA EDUCAÇÃO (ANFOPE). Posição da ANFOPE sobre a BNCC. Brasília: Anfope, 2017. Disponível em: http://www.anfope.org.br/wp-content/uploads/2018/05/CARTA-deBrasilia_ANFOPE-V-Audiencia-Publica-CNE.-11.9.2017.pdf. Acesso em: 29 abr. 2020.

ASSOCIAÇÃO NACIONAL DE PÓS-GRADUAÇÃO E PESQUISA EM EDUCAÇÃO (ANPED). ANPEd e a BNCC: luta, resistência e negação. Rio de Janeiro: ANPEd, 2020. Disponível em: http://www.anped.org.br/content/anped-e-bncc-lutaresistencia-e-negacao. Acesso em: 29 abril 2020.

AYRES, A. C. M., (2004). A formação de professores para o Ensino Secundário no Brasil: recuperando uma trajetória de tensão entre três elementos - escola, universidade e sociedade. Niterói: FE/UFF.

BARDIN, L. Análise de conteúdo. Lisboa: Edições 70, 2000.

BARBOSA, A. T.; CASSIANI, S. A prática como componente curricular em um curso de formação de professores de Biologia: sentidos e possibilidades. In: MOHR, A.; WIELEWICKI, H. de G. (Orgs.) Prática como componente curricular: que novidade é essa 15 anos depois? 1. ed. Florianópolis: NUP/CED/UFSC, 2017, p. 171-192.

BEGO, A. M.; OLIVEIRA, R. C.; CORRÊA, R. G. O papel da Prática como Componente Curricular na formação inicial de professores de Química: possibilidades de inovação didático-pedagógica. Química Nova Escola, São Paulo, v. 39, n. 3, p. 250-260, ago. 2017.

BIZARRO, A. M. S. Estágio supervisionado e prática na formação inicial das licenciaturas da UPE-FACETEG: construindo saberes a partir da legislação. In: XXV Simpósio Brasileiro, 25 e Congresso Ibero-Americano de Política e Administração da Educação, 2, 2011, São Paulo - SP. Anais [...] São Paulo - SP, 2011.

BOGDAN, R.; BIKLEN, S. K. Investigação qualitativa em educação. Portugal: Porto editora, 1991. componente curricular em cursos de Biologia. ACTIO: Docência em Ciências, Curitiba, v. 4, n. 1, p. 127-147, jan./abr. 2019. 
BRASIL. Ministério da Educação. Conselho Nacional de Educação. Resolução CNE/CP 1/2002. Diário Oficial da União. Brasília, 2002a.

BRASIL. Ministério da Educação. Conselho Nacional de Educação. Resolução CNE/CP 2/2002. Diário Oficial da União. Brasília, 2002b.

BRASIL. Ministério da Educação. Conselho Nacional de Educação. Câmara de Educação Superior. Resolução CNE/CES 7/2002. Diário Oficial da União. Brasília, 2002c.

BRASIL. Ministério da Educação. Conselho Nacional de Educação. Resolução CNE/CP 2/2015. Diário Oficial da União. Brasília, 2015a.

BRASIL. Ministério da Educação. Conselho Nacional de Educação. Resolução CNE/CP 2, 2017. Diário Oficial da União. Brasília: CNE, 2017.

BRASIL. Ministério da Educação. Conselho Nacional de Educação. Resolução CNE/CP no 2/2019. Diário Oficial da União. Brasília, $2019 b$.

BRASIL. Ministério da Educação. Conselho Nacional de Educação. Parecer CNE/CP 28/2001. Diário Oficial da União. Brasília, 2001a.

BRASIL. Ministério da Educação. Conselho Nacional de Educação. Parecer 1.301/2001. Diário Oficial da União. Brasília, 2001b.

BRASIL. Ministério da Educação. Conselho Nacional de Educação. Parecer CNE/CES 15/2005. Diário Oficial da União. Brasília, 2005.

BRASIL. Ministério da Educação. Parecer CNE/CP 2/2015. Diário Oficial da União. Brasília, 2015b.

BRASIL. Ministério da Educação. Conselho Nacional de Educação. Parecer CNE/CP 22/2019. Diário Oficial da União. Brasília, 2019a.

BRASIL. Ministério da Educação. Lei de Diretrizes e Bases da Educação Nacional. Lei número 9394, 20 de dezembro de 1996. Diário Oficial da União. Brasília, 1996.

BRITO, L. D. A configuração da "prática como componente curricular" nos cursos de licenciatura em Ciências Biológicas das universidades estaduais da Bahia.

2011. 154 f. Tese (Doutorado em Educação) - Faculdade de Educação, Universidade Federal de São Carlos-UFSCAR, São Carlos, SP, 2011.

CALIXTO, V. dos S.; KIOURANIS, N. M. M. Prática como Componente Curricular: as lentes que constituem os óculos dos formadores de professores de Química. In: Encontro Nacional de Pesquisa em Educação em Ciências, 11, Florianópolis - SC. Anais [...] Florianópolis - SC, 2017.

CARVALHO, A. M. P.; GIL-PÉREZ, D.; de. Formação de professores de Ciências: 
DUTRA, E. F. Possibilidades para articulação entre teoria e prática em cursos de Licenciaturas. 2010. 354 f. Dissertação (Mestrado em Educação) - Universidade Federal de Santa Maria, Santa Maria, 2010.

FÁVERO, M. DE L. Sobre a formação do educador. In: MENDONÇA, A. W. P. C.; FÁVERO, M. de L. de A.; CANDAU, V. M. F.; FIRME, T. P.; ABRAMOVAY, M.; KRAMER, S.; STHAL, M. M. A formação do educador: desafios e perspectivas. Rio de Janeiro, PUC/RJ, 1981.

FRACALANZA, H.; AMARAL, I.A.; GOUVEIA, M. S. F. O ensino de ciências no 10 grau. São Paulo: Atual, 1986.

GARCIA, C. M. Formación del profesorado pare el cambio educativo. Barcelona: P.P.U., 1994.

GAUTHIER, C.; MARTINEAU, S.; DESBIENS, J-F.; MALO, A.; SIMARD, D. Por uma teoria da pedagogia: pesquisas contemporâneas sobre o saber docente. ljuí: Ed. UNIJUÍ, 1998.

GIL, A. C. Métodos e técnicas de pesquisa social. 6. ed. São Paulo: Atlas, 2008.

GOEDERT, L. A formação do professor de Biologia e o ensino da Evolução Biológica. 2004. 122 f. Dissertação (Mestrado em Educação Científica e Tecnológica) - Universidade Federal de Santa Catarina, Florianópolis, 2004.

KRASILCHIK, M. O professor e o currículo das ciências. São Paulo: EPU/EDUSP, 1987.

LIBÂNEO, J. C. Educação: pedagogia e didática - o campo investigativo da pedagogia e da didática no Brasil - esboço histórico e buscas de identidade epistemológica e profissional. In: PIMENTA, S. G. (Org.). Didática e formação de professores: percursos e perspectivas no Brasil e em Portugal. São Paulo: Cortez, 1997. p. 77-129.

MADEIRA, A. V. M. Hibridismo epistemológico e formativo na Licenciatura em Ciências Biológicas: como os docentes de disciplinas específicas se implicam na articulação da formação inicial com a prática profissional. 2014. 141 f. Tese (Doutorado em Educação) - Universidade Federal da Bahia, Salvador, 2014.

MOHR, A.; CASSIANI, S. Concepção, proposta e execução da prática como componente curricular no curso de graduação de Ciências Biológicas da Universidade Federal de Santa Catarina. In: MOHR, A.; WIELEWICKI, H. de G. (Orgs.) Prática como componente curricular: que novidade é essa 15 anos depois? 1. ed. Florianópolis: NUP/CED/UFSC, 2017, p. 61-86.

MOHR, A.; WIELEWICKI, H. de G. Apresentação. In: MOHR, A.; WIELEWICKI, H. de G. (Orgs.) Prática como componente curricular: que novidade é essa 15 anos depois? 1. ed. Florianópolis: NUP/CED/UFSC, 2017, s/p. 
MOROSINI; M. C.; FERNANDES, C. M. B. Estado do Conhecimento: conceitos, finalidades e interlocuções. Educação Por Escrito, Porto Alegre, v. 5, n. 2, p. 154164, jul./dez. 2014.

NÓVOA, A. Formação de professores e profissão docente. In: NÓVOA, A. (Org.) Os professores e a sua formação. Lisboa: Publicações Dom Quixote, 1992.

OLIVEIRA, G. S. Prática como componente curricular (PCC) nas licenciaturas em Ciências Biológicas: espaço/tempo de aprendizagem profissional? Debates em Educação, Maceió, v. 6, n. 12, p. 19-37, jul./dez. 2014.

PÁDUA, E. M. M. Metodologia da pesquisa: abordagem teórico-prática. 2. ed. São Paulo: Papirus, 1997.

PEREIRA, J. E. D. As licenciaturas e as novas políticas educacionais para a formação. Educação \& Sociedade, Campinas, ano XX, no 68, p. 109-125, dez./99.

PERRENOUD, P.; PAQUAY, L.; ALTET, M.; CHARLIER, E. Formando professores profissionais: três conjuntos de questões. In: LÉOPOLD, P.; PERRENOUD, P.; ALTET, M.; CHARLIER, E. (Org.). Formando professores profissionais: quais estratégias? Quais competências? Trad. Fátima Murad e Eunice Gruman. 2. ed. rev. Porto Alegre: Artmed, 2001, p. 11-22.

PEREIRA, B.; Mohr, A. Origem e contornos da prática como componente curricular. In: MOHR, A.; WIELEWICKI, H. de G. (Orgs.) Prática como componente curricular: que novidade é essa 15 anos depois? 1. ed. Florianópolis: NUP/CED/UFSC, 2017, p. 19-38.

ROMANOWSKI, J. P.; ENS, R. T. As pesquisas denominadas do tipo "Estado da Arte" em Educação. Diálogo Educacional, Curitiba, v. 6, n.19, p. 37-50, set./dez. 2006.

SÁ, C. S. DA S.; SANTOS, W. L. P. DOS. A identidade de um curso de formação de professores de Química. In: Encontro Nacional de Pesquisa em Educação em Ciências, 7. Anais [...] Florianópolis-SC, 2009.

SAVIANI, D. A pós-graduação em educação no Brasil: pensando o problema da orientação. 2010. Disponível em: https://oplum2.wordpress.com/2010/09/15/apos-graduacao-em-educacao-no-brasil-pensando-o-problema-da-orientacaodermeval-saviani/. Acesso em: 25 out. 2018.

SCHNETZLER, R. P. A pesquisa em ensino de Química no Brasil: conquistas e perspectivas. Química Nova, v. 25, supl. 1, p. 14-24, 2002.

SILVÉRIO, L. E. R. As práticas pedagógicas e os saberes da docência na formação acadêmico-profissional em Ciências Biológicas. 2014. 486 f. Tese (Doutorado em Educação Científica e Tecnológica) - Universidade Federal de Santa Catarina, Florianópolis, 2014.

SILVÉRIO, L. E. R. Prática como componente curricular: desafios e possibilidades da integração da formação acadêmica com o campo profissional da docência. In: 
MOHR, A.; WIELEWICKI, H. de G. (Orgs.) Prática como componente curricular: que novidade é essa 15 anos depois? 1. ed. Florianópolis: NUP/CED/UFSC, 2017, p.151-170.

SLONGO, I. I. A produção acadêmica em ensino de Biologia: um estudo a partir de dissertações e teses. Relatório do exame de qualificação para doutorado. Centro de Ciências da Educação, UFSC, Florianópolis, 2003.

SOARES, M. B; MACIEL, F. Alfabetização. Brasília: MEC/Inep/ Comped, 2000. (Série Estado do Conhecimento, n. 1)

TARDIF, M. Saberes docentes e formação profissional. 4. ed. Petrópolis: Vozes, 2002.

TEIXEIRA, P. M. M.; MEGID NETO, J. Investigando a pesquisa educacional: um estudo enfocando dissertações e teses sobre o ensino de Biologia no Brasil. Investigações em Ensino de Ciências, Porto Alegre, v. 11, n. 2, p. 261-282, 2006.

TOLENTINO, P. C. Os estudos ciência, tecnologia e sociedade e a prática como componente curricular: tensões, desafios e possibilidades na formação de professores nas Ciências Biológicas. 2017. 335 f. Tese (Doutorado em Educação Científica e Tecnológica) - Universidade Federal de Santa Catarina, Florianópolis, 2017.

TORRES, J. R. Prática como componente curricular em dois cursos de licenciatura em Ciências Biológicas da UFSCAR - campus Sorocaba. In: MOHR, A.; WIELEWICKI, H. de G. (Orgs.) Prática como componente curricular: que novidade é essa 15 anos depois? 1. ed. Florianópolis: NUP/CED/UFSC, 2017, p.107-122.

TORRES, J. R.; SILVÉRIO, L. E. R.; MAESTRELLI, S. R. P. A prática como componente curricular no curso de graduação de Ciências Biológicas da UFSC: um diagnóstico inicial. In: MOHR, A.; WIELEWICKI, H. de G. (Orgs.) Prática como componente curricular: que novidade é essa 15 anos depois? 1. ed. Florianópolis: NUP/CED/UFSC, 2017, p.211-242.

VIANA, G. M.; COUTINHO, F. Â. Prática como componente curricular: seguindo o conceito e analisando sua performance no currículo do curso de licenciatura em Ciências Biológicas da UFSJ. In: MOHR, A.; WIELEWICKI, H. de G. (Orgs.) Prática como componente curricular: que novidade é essa 15 anos depois? 1. ed. Florianópolis: NUP/CED/UFSC, 2017, p.243-262. 
Recebido: 10 mar. 2020

Aprovado: 12 mai. 2020

DOI: 10.3895/actio.v5n2.11749

Como citar:

OLIVEIRA, J. M. P. de.; GIANOTTO, D. E. P. A prática como componente curricular na formação de professores em ciências biológicas: o que revelam as teses e dissertações. ACTIO, Curitiba, v. 5, n. 2, p. 1 -

24, mai./ago. 2020. Disponível em: <https://periodicos.utfpr.edu.br/actio>. Acesso em: XXX

Correspondência:

Juliana Moreira Prudente de Oliveira

Rua Universitária, n. 1619, Jardim Universitário, Cascavel, Paraná, Brasil.

Direito autoral: Este artigo está licenciado sob os termos da Licença Creative Commons-Atribuição 4.0

Internacional.

(c) (1) 